\title{
A Meta-analysis for Evaluating Efficacy of Neuroendoscopic Surgery versus Craniotomy for Supratentorial Hypertensive Intracerebral Hemorrhage
}

\author{
Taek Min Nam, Young Zoon Kim \\ Department of Neurosurgery, Samsung Changwon Hospital, Sungkyunkwan University School of Medicine, Changwon, \\ South Korea
}

\begin{abstract}
Objective : Hypertensive intracerebral hemorrhage is a potentially life-threatening neurological deficit with the highest morbidity and mortality. In recent years, neuroendoscopy has been used to treat intracerebral hemorrhages (ICHs). However, the choice of neuroendoscopic surgery or craniotomy for patients with ICHs is controversial. The objective of this meta-analysis was to assess the efficacy of neuroendoscopic surgery compared to craniotomy in patients with supratentorial hypertensive $\mathrm{ICH}$.

Materials and Methods : A systematic electronic search was performed using online electronic databases such as Pubmed, Embase, and Cochrane library updated on December 2017. The meta-analysis was performed by only including studies designed as randomized controlled trials.

Results : Three randomized controlled trials met our inclusion criteria. Pooled analysis of death showed that neuroendoscopic surgery decreased the rate of death compared to craniotomy $(\mathrm{RR}=0.58,95 \% \mathrm{Cl}$ : $0.26-1.29$; $\mathrm{P}=0.18$ ). Pooled results of complications showed that neuroendoscopic surgery tended to have fewer complications than craniotomy had (RR $=0.37$, 95\% Cl: 0.28-0.49; $\mathrm{P}<0.0001$ ).

Conclusions : Although the presenting analyses suggest that neuroendoscopic surgery should have fewer complications than craniotomy dose, it had no superior advantage in morbidity rate definitely. Therefore, it may be necessary for the neurosurgeons to select best optimal patients for individual treatment.
\end{abstract}

Keywords craniotomy, hypertensive intracerebral hemorrhage, neuroendoscopic surgery, meta-analysis, efficacy
J Cerebrovasc Endovasc Neurosurg.

2019 March;21(1):11-17

Received : 13 March 2019

Revised : 26 March 2019

Accepted : 28 March 2019

\section{Correspondence to Young Zoon Kim}

Department of Neurosurgery, Samsung

Changwon Hospital, Sungkyunkwan University

School of Medicine, 158, Paryong-ro, Masanhoewongu,

Changwon, 51353, South Korea

\author{
Tel : $+82-55-233-5241$ \\ Fax : $+82-55-233-8070$ \\ E-mail : yzkim@skku.edu \\ ORCID : http://orcid.org/0000-0001-9724-3081
}

This is an Open Access article distributed under the terms of the Creative Commons Attribution NonCommercial License (http://creativecommons.org/licenses/by-nc/3.0) which permits unrestricted noncommercial use, distribution, and reproduction in any medium, provided the original work is properly cited.

\section{INTRODUCTION}

Hypertensive intracerebral hemorrhage $(\mathrm{HICH})$ is a condition that can cause high mortality rate ${ }^{7}$ and severe disabilities ${ }^{2223)}$. Management of primary intracerebral hemorrhage remains controversial. Previous studies have shown that neurosurgical treatment rath- er than conservative treatment is associated with better outcomes $(\mathrm{P}<0.001)^{17)}$ for $\mathrm{HICH}$. To treat $\mathrm{HICH}$, surgical procedures have been employed. However, their results are not strongly established as well as heterogeneous among studies. To dates, several studies have reported different strategies of neurosurgical interventions, including craniotomy and neuro- 
endoscopic surgery ${ }^{23321) 24)}$.

In the past several decades, craniotomy played critical roles in treatment of $\mathrm{HICH}$. However, several prospective randomized controlled trials have failed to show benefit of craniotomy for treating $\mathrm{HICH}$ patients ${ }^{16) 21)}$. Endoscopic surgery has been also applied in the treatment of $\mathrm{HICH}$ in recent years. Many studies have suggested that endoscopic evacuation of $\mathrm{HICH}$ should have better outcomes and more safety for $\mathrm{HICH}$ patients ${ }^{518)}$ than traditional craniotomy ${ }^{2326)}$. However, due to retrospective nature of research or limited sample size, no concrete conclusion could be drawn about effects of endoscopic surgery on outcomes of $\mathrm{HICH}$ patients ${ }^{125)}$.

Therefore, the objective of this meta-analysis was to compare craniotomy and neuroendoscopic surgery to determine which one might be safer and more effective in promoting outcomes and reducing complications in patients with HICHs.

\section{METHODS AND MATERIALS}

\section{Retrieval strategy}

Published articles that compared efficacy and safety of neuroendoscopic surgery and craniotomy in patients with supratentorial HICH up to December 2017 were retrieved. Searchable databases included Pubmed, Embase, and Cochrane library. The process was established to find all articles based on MeSH terms and keywords of "craniotomy", "neuroendoscopic surgery" and "hypertensive intracerebral hemorrhage". No limitation was used during literature search. We identified full-text papers from reference materials for further evaluation.

\section{Eligibility criteria}

Articles that met the following inclusion criteria were included in this analysis: (1) studies that were designed as randomized controlled trials; (2) articles that enrolled hypertensive intracerebral hemorrhage patients; (3) trials that compared craniotomy to neuroendoscopic surgery; and (4) studies that provided da- ta of perioperative morbidity or mortality. Studies that did not meet the above inclusion criteria were excluded from meta-analysis.

\section{Quality assessment}

Two investigators independently rated the quality of retrieved studies. Risk of bias items (ROBI) recommended by the Cochrane Handbook for Systematic Reviews of Interventions were chosen.

\section{Data extraction}

Data were extracted by two authors independently. Disagreement was revolved by consensus. From each eligible study, data of the following were extracted: first author family name, publication year, study total number, mean age, hematoma volume $(\mathrm{mL})$, and death number.

Ethical approval was waived because this study did not involve human participants or animals. Informed consent was not required because no human participant was involved in this study.

\section{Statistical analysis}

Meta-analysis was performed by pooling results of reported incidence of death and morbidity of the individual therapeutic modality. Results are expressed as appropriate ratio/difference for dichotomous outcomes based on available data. The I2 statistic test was performed to further examine statistical heterogeneity between trials ${ }^{8)}$. Studies with an I2 $\geq 50 \%$ were considered to have moderate and high heterogeneity while those with $\mathrm{I} 2<50 \%$ were considered to have low heterogeneity ${ }^{9}$. Random-effect model was adopted if I $2>50 \%$. Otherwise, fixed-effect model was chosen.

Statistical significance was considered when $\mathrm{P}$ value was less than 0.05. All meta-analyses were performed using Review Manager Version 5.3 software (Revman; The Cochrane collaboration Oxford, United Kingdom). Findings of our meta-analysis are shown in forest plots. The risk of bias was evaluated using Begg's test and Egger's test. 


\section{RESULTS}

Overview of literature search and study characteristics

A total of 213 studies were initially found after primary selection. Based on inclusion criteria, 206 irrelevant citations were excluded after reviewing titles and abstracts. Finally, a total of three RCTs ${ }^{56) 27}$ were included in this meta-analysis (Fig. 1). These eligible studies included 289 subjects who underwent neuroendoscopic evacuation of supratentorial $\mathrm{HICH}$ and craniotomy with removal of $\mathrm{HICH}$ (Table 1). Among them, 144 subjects were treated with neuroendoscopic surgery and 145 subjects were treated with craniotomy and removal of $\mathrm{HICH}$. The mean age was 64.1 years old; 63.4 years old in patients who underwent neuroendoscopic surgery and 64.8 years old in patients who underwent craniotomy $(\mathrm{P}=0.758)$. The mean volume of $\mathrm{HICH}$ was $53.7 \mathrm{~mL} ; 56.6 \mathrm{~mL}$ in patients who underwent neuroendoscopic surgery and $51.0 \mathrm{~mL}$ years old in patients who underwent craniotomy $(\mathrm{P}=0.264)$. The operating time was 103.4 minutes in patients who underwent neuroendoscopic surgery and 205.7 minutes years old in patients who underwent craniotomy $(\mathrm{P}=0.019)$. The mean rate of hematoma evacuation was $81.7 \% ; 85.2 \%$ in patients who underwent neuroendoscopic surgery and $78.2 \%$ in patients who underwent craniotomy $(\mathrm{P}=0.184)$. Preoperative

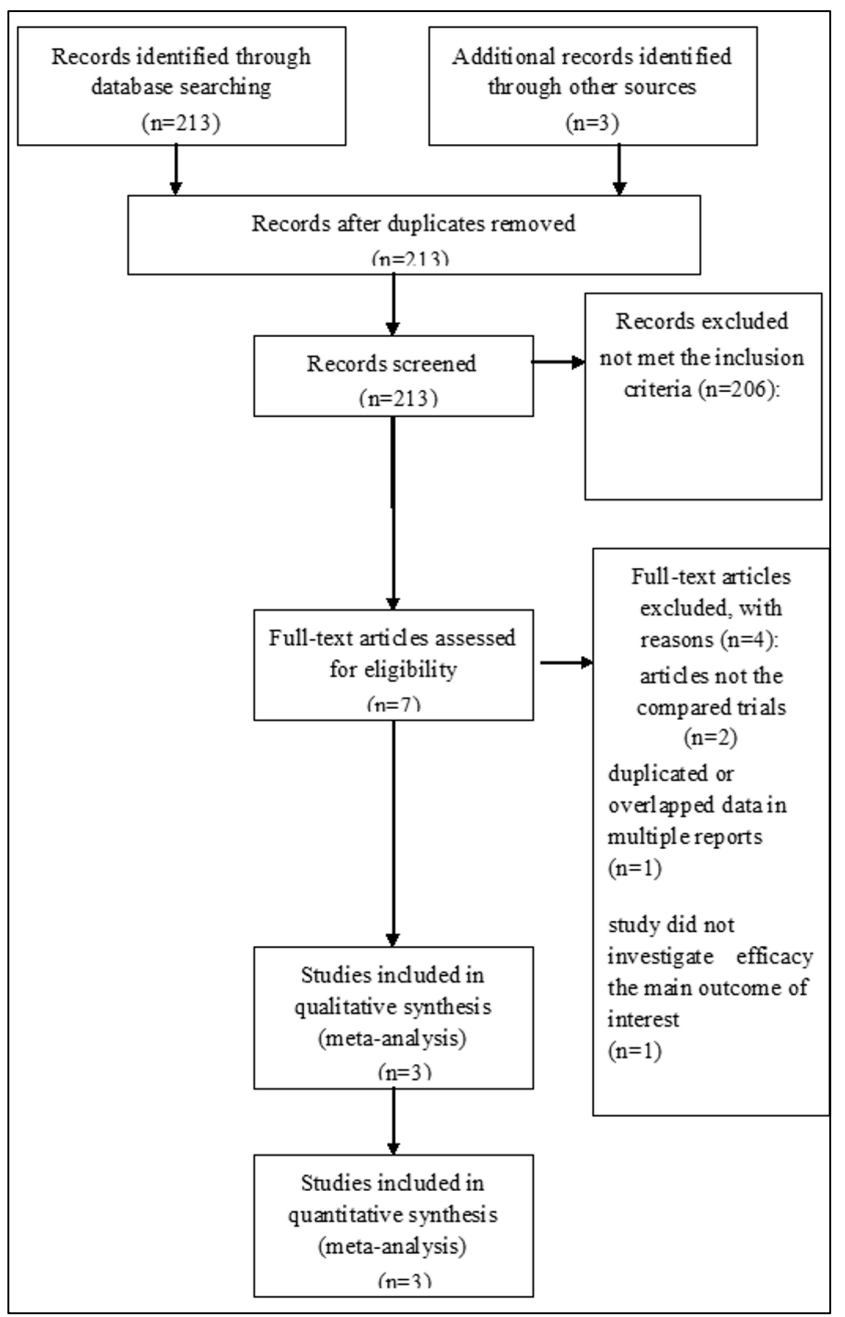

Fig. 1. PRISMA flow chart of selection process to identify studies eligible for pooling.

Table 1. The primary characteristics of the eligible studies in more detail

\begin{tabular}{|c|c|c|c|c|c|c|}
\hline & \multicolumn{2}{|c|}{ Feng Y, et al. 2016} & \multicolumn{2}{|c|}{ Zhang HZ, et al. 2014} & \multicolumn{2}{|c|}{ Cho DY, et al. 2006} \\
\hline & NE & $\mathrm{C} / \mathrm{O}$ & NE & $\mathrm{C} / \mathrm{O}$ & NE & $\mathrm{C} / \mathrm{O}$ \\
\hline Total number of patients & 93 & 91 & 21 & 24 & 30 & 30 \\
\hline Male/Female & $56 / 37$ & $58 / 33$ & $16 / 5$ & $22 / 8$ & $19 / 11$ & $21 / 9$ \\
\hline Mean age (year) & 66.35 & 69.1 & 59.9 & 61.5 & 56.7 & 54.2 \\
\hline Hematoma volume (ml) & & & 58.28 & 62.16 & 55.48 & 42.11 \\
\hline Right/Left & & & & & $20 / 10$ & $18 / 12$ \\
\hline Involvement of Thalamus & & & & & 9 & 5 \\
\hline Intraventricular hemorrhage & & & & & 12 & 10 \\
\hline Operating time (minutes) & $91.8 \pm 31.2$ & $205.8 \pm 39$ & $76.5 \pm 14.9$ & $175.2 \pm 26.1$ & $158.1 \pm 47.4$ & $230.0 \pm 50.6$ \\
\hline Evacuation rate (\%) & $83.5 \pm 27.5$ & $77.3 \pm 13.4$ & $90.1 \pm 7.3$ & $85.4 \pm 6.8$ & $87 \pm 8$ & $75 \pm 2$ \\
\hline Preoperative GCS & & & $9.2 \pm 3.8$ & $8.4 \pm 2.4$ & $9.3 \pm 1.2$ & $9.3 \pm 1.0$ \\
\hline Postoperative GCS & & & $9.7 \pm 2.6$ & $9.0 \pm 2.9$ & $14.5 \pm 1.0$ & $14.2 \pm 1.8$ \\
\hline Rebleeding rate (\%) & 6.5 & 3.3 & 4.8 & 10.0 & & \\
\hline Infection rate $(\%)$ & & & 9.5 & 36.7 & & \\
\hline Mean GOS at 6 months & 4.2 & 3.9 & $3.6 \pm 0.9$ & $3.1 \pm 1.3$ & & \\
\hline
\end{tabular}

C/O, craniotomy; GCS, Glasgow Coma Scale; GOS, Glasgow Outcome Scale; NE, neuroendoscopy 
Glasgow Coma Scale (GCS) was 9.17; 9.26 in patients who underwent neuroendoscopic surgery and 8.90 patients who underwent craniotomy $(\mathrm{P}=0.615)$. Postoperative GCS was 12.23; 12.52 in patients who underwent neuroendoscopic surgery and 11.89 in patients who underwent craniotomy $(\mathrm{P}=0.759)$.

\section{Clinical and methodological heterogeneity}

1. Pooled analysis of death after neuroendoscopic surgery compare with craniotomy

The Odds Ratio (OD) was 0.10 (95\% confidence interval [CI]: 0.00-1.88) in Cho's study, 0.98 (95\% CI: 0.35-2.72) in Feng's study, and 0.18 (95\% CI: 0.01-3.73) in Zhang's study. Pooling analysis ${ }^{56) 27}$ revealed that there was no statistically significant difference in death between neuroendoscopic surgery and craniotomy $(\mathrm{OR}=0.56,95 \% \mathrm{CI}$ : 0.24-1.31; $\mathrm{P}=0.18)$ (Fig. 2).

2. Pooled analysis of complication after neuroendoscopic surgery compare with craniotomy

The Odds Ratio (OD) was 0.17 (95\% CI: 0.02-1.18) in Cho's study, 0.08 (95\% CI: 0.04-0.17) in Feng's study, and 0.19 (95\% CI: 0.01-0.79) in Zhang's study. Random-effects model was used to pool complication data $^{56) 27)}$. Pooled data showed that neuroendoscopic surgery had lower risk of complications than craniotomy $(\mathrm{OR}=0.11,95 \% \mathrm{CI}$ : 0.06-0.20; $\mathrm{P}<0.00001)$ (Fig. 3).

\section{DISCUSSION}

Hypertensive intracerebral hemorrhage is a major health burden with the highest morbidity and mortality. In case of a massive hematoma, neurosurgical drainage is a crucial therapeutic option. Endoscopic evacuation in comparison with traditional craniotomy has been investigated ${ }^{5)}$. However, many questions regarding minimally invasive surgery remain unanswered. Historically, craniotomy has been used as an appropriate therapy to treat $\mathrm{HICH}^{4)}$. A recent RCT has shown that early craniotomy surgery might reduce mortality of $\mathrm{ICH}$ patients ${ }^{17)}$. Craniotomy also has some advantages such as good view and immediate removal of hematoma with improvement in local blood circulation ${ }^{19)}$ that could improve outcomes. However, there is no more studies showing good results neither any improvement of the outcome in

\begin{tabular}{|c|c|c|c|c|c|c|c|c|c|c|}
\hline Study or Subgroup & $\begin{array}{l}\text { Experim } \\
\text { Events }\end{array}$ & $\begin{array}{l}\text { ental } \\
\text { Total }\end{array}$ & $\begin{array}{l}\text { Contr } \\
\text { Events }\end{array}$ & $\begin{array}{l}\text { ol } \\
\text { Total }\end{array}$ & Weight & $\begin{array}{c}\text { Odds Ratio } \\
\text { M-H, Fixed, 95\% CI }\end{array}$ & & $\begin{array}{r}\text { Odds } \mathrm{F} \\
\mathrm{M}-\mathrm{H}, \text { Fixed }\end{array}$ & $\begin{array}{l}\text { Ratio } \\
\text { d, } 95 \% \mathrm{Cl}\end{array}$ & \\
\hline Cho DY 2006 & 0 & 30 & 4 & 30 & $30.2 \%$ & $0.10[0.00,1.88]$ & & & & \\
\hline Feng Y 2016 & 8 & 93 & 8 & 91 & $50.4 \%$ & $0.98[0.35,2.72]$ & & & & \\
\hline Zhang HZ 2014 & 0 & 21 & 3 & 30 & $19.4 \%$ & $0.18[0.01,3.73]$ & & & & \\
\hline Total $(95 \% \mathrm{CI})$ & & 144 & & 151 & $100.0 \%$ & $0.56[0.24,1.31]$ & & & & \\
\hline Total events & 8 & & 15 & & & & & & & \\
\hline \multicolumn{7}{|c|}{$\begin{array}{l}\text { Heterogeneity: } \mathrm{Chi}^{2}=3.02, \mathrm{df}=2(P=0.22) ; \mathrm{I}^{2}=34 \% \\
\text { Test for overall effect: } \mathrm{Z}=1.34(\mathrm{P}=0.18)\end{array}$} & 0.10 .2 & $0.5 \mathrm{NE}^{1}$ & $\frac{2}{\text { craniotomy }}$ & $\overrightarrow{10}$ \\
\hline
\end{tabular}

Fig. 2. Pooled analysis of death after neuroendoscopic surgery compare with craniotomy

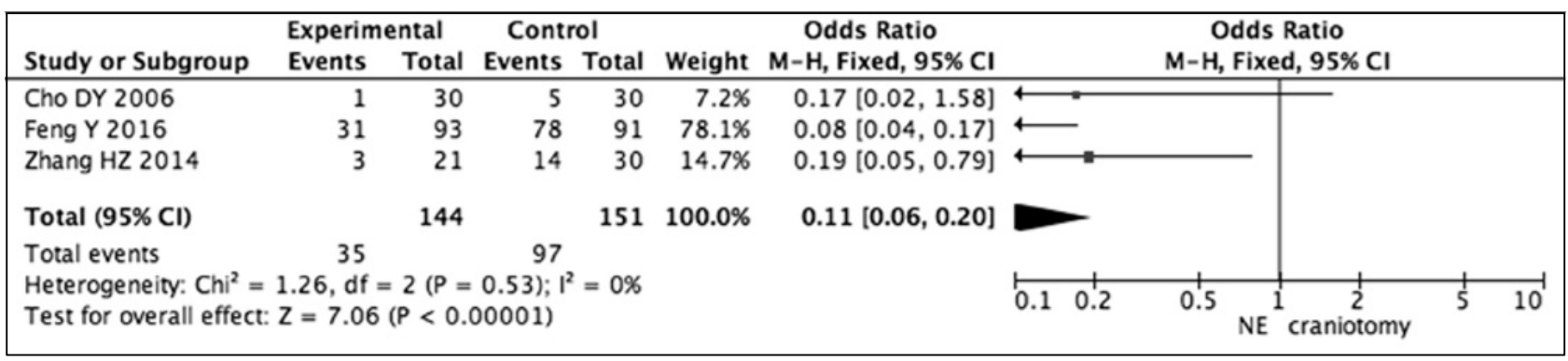

Fig. 3. Pooled analysis of complication after neuroendoscopic surgery compare with craniotomy 
$\mathrm{HICH}$ patients who underwent craniotomy and removal of ICH. Because of the lack of large multi-centric $\mathrm{RCTs}^{7}$, many surgical trials have shown that craniotomy is associated with substantial toxicity ${ }^{10) 12220)}$. The shortcoming of craniotomy is that it increases operation time and the risk of infection. Therefore, it is necessary that a minimally invasive surgery causing minimal trauma to normal brain region during the process of removal of hematoma should replace craniotomy to treat $\mathrm{HICH}^{13)}$.

During neuroendoscopic surgery as a minimally invasive procedure, a small burr hole is created and a 5 to 8 -mm-diameter endoscope is inserted into the brain tissue ${ }^{25}$. This minimal invasive surgery is performed using an operation endoscope, which has benefit of keeping normal hemostasis of brain and little damage for the skull due to making small bony window compared to craniotomy. Neuroendoscopic surgery has been successfully applied for hematoma evacuation with many advantages ${ }^{28)}$. Some scholars have emphasized that hemorrhage position, hemorrhage volume, and patient condition should be considered in the selection of surgical method ${ }^{1114)}$. Appropriate operative route is the key to achieve successful treatment of $\mathrm{HICH}$. As neuroendoscopic removal of $\mathrm{HICH}$ is preceded within the cavity, it is possible to perform minimally invasive interventions for brain tissues regardless whether these tissues are normal or surrounded by damaged region ${ }^{27}$.

Regarding the incidence of complications, we found that patients who had undergone neuroendoscopic surgery had fewer complications than those who had undergone craniotomy. The patients who underwent neuroendoscopic evacuation of $\mathrm{HICH}$ had lower rate of infectious complications. The reason for this benefit includes the following: (a) neuroendoscopy provides multi-angle observation and "observe around the corner" capability to manage intraoperative bleeding which make up for the insufficiency of direct vision'); and (b) in some studies, to avoid brain tissue damage, some authors have selected short and precise routes to remove hematomas under direct vision and deep lesions without manipulating or exposing unaffected $\operatorname{areas}^{27}$.

Although this meta-analysis showed that the neuroendoscopic surgery should have a benefit compared with the craniotomy for $\mathrm{HICH}$, there is several limitations for application in the practice. Mainly, only three RCTs were eligible for presenting analysis. The parameters were not completely homogeneous. Even several parameters were obtained only one RCT such as anatomical involvement of hemorrhage into the thalamus and ventricle which has meaningful parameter for evaluation of postoperative neurological outcome. And the enrolled patient's age was also different; the Feng's analysis was subjected to the elderly patients with age of 65 to 79 years. The initial neurological status was somewhat different from individual study; the Cho's study was performed in the noncomatose patients. Even the design of Cho's study included patients who underwent stereotactic aspiration. In fact, the parameters for patient's clinical characteristics which were extracted homogenously were only gender, and age of patient. And for the analysis of clinical outcome, the complication and the mortality were parameters which were completely extracted from three RCTs. Therefore, the presenting meta-analysis can show the comparative results in these limited parameters such as postoperative mortality and complications. To overcome above limitation, it is mandatory that further randomized clinical trials should verify the efficacy of neuroendoscopic approach for $\mathrm{HICH}$ in the future.

\section{CONCLUSION}

Our results suggest that neuroendoscopic surgery can significantly reduce the rate of complications in patients with $\mathrm{HICH}$ compared to craniotomy, although it does not improve death outcome. When all data were analyzed, it became obvious that these two methods had their own advantages and shortcomings. 
Each had its own indications. It is difficult to decide which one is better for $\mathrm{HICH}$ patients. Thus, it is essential to select individualized treatment for each patient. Eligible randomized clinical trials are needed to verify the efficacy of neuroendoscopic approach for $\mathrm{HICH}$ in the future.

\section{ACKNOWLEDGEMENT}

\section{Funding:}

No funding was received for this research.

\section{Conflict of Interest:}

All authors certify that they have no affiliations with or involvement in any organization or entity with any financial interest (such as honoraria; educational grants; participation in speakers' bureaus; membership, employment, consultancies, stock ownership, or other equity interest; and expert testimony or patent-licensing arrangements), or non-financial interest (such as personal or professional relationships, affiliations, knowledge or beliefs) in the subject matter or materials discussed in this manuscript.

\section{REFERENCES}

1. Auer LM, Deinsberger W, Niederkorn K, Gell G, Kleinert R, Schneider G, et al. Endoscopic surgery versus medical treatment for spontaneous intracerebral hematoma: a randomized study. J Neurosurg. 1989 Apr;70(4):530-5.

2. Batjer HH, Reisch JS, Allen BC, Plaizier LJ, Su CJ. Failure of surgery to improve outcome in hypertensive putaminal hemorrhage. A prospective randomized trial. Arch Neurol. 1990 Oct;47(10):1103-6.

3. Bhattathiri PS, Gregson B, Prasad KS, Mendelow AD, Investigators $\mathrm{S}$. Intraventricular hemorrhage and hydrocephalus after spontaneous intracerebral hemorrhage: results from the STICH trial. Acta Neurochir Suppl. 2006;96:65-8.

4. Bosel J, Zweckberger K, Hacke W. Haemorrhage and hemicraniectomy: refining surgery for stroke. Curr Opin Neurol. 2015 Feb;28(1):16-22.

5. Cho DY, Chen CC, Chang CS, Lee WY, Tso M. Endoscopic surgery for spontaneous basal ganglia hemorrhage: comparing endoscopic surgery, stereotactic aspiration, and craniotomy in noncomatose patients. Surg Neurol. 2006 Jun;65(6):547-55; discussion 555-6.

6. Feng Y, He J, Liu B, Yang L, Wang Y. Endoscope-Assisted
Keyhole Technique for Hypertensive Cerebral Hemorrhage in Elderly Patients: A Randomized Controlled Study in 184 Patients. Turk Neurosurg. 2016;26(1):84-9.

7. Hemphill JC, 3rd, Greenberg SM, Anderson CS, Becker $\mathrm{K}$, Bendok BR, Cushman M, et al. Guidelines for the Management of Spontaneous Intracerebral Hemorrhage: A Guideline for Healthcare Professionals from the American Heart Association/American Stroke Association. Stroke. 2015 Jul;46(7):2032-60.

8. Higgins JP, Thompson SG. Quantifying heterogeneity in a meta-analysis. Stat Med. 2002 Jun 15;21(11):1539-58.

9. Higgins JP, Thompson SG, Deeks JJ, Altman DG. Measuring inconsistency in meta-analyses. BMJ. 2003 Sep 6;327(7414):557-60.

10. Lee JI, Nam DH, Kim JS, Hong SC, Shin HJ, Park K, et al. Stereotactic aspiration of intracerebral haematoma: significance of surgical timing and haematoma volume reduction. J Clin Neurosci. 2003 Jul;10(4):439-43.

11. Li F, Chen QX. Risk factors for mental disorders in patients with hypertensive intracerebral hemorrhage following neurosurgical treatment. J Neurol Sci. 2014 Jun;341 (1-2):128-32.

12. Li Q, Yang $\mathrm{CH}, \mathrm{Xu} \mathrm{JG}, \mathrm{Li} \mathrm{H}$, You C. Surgical treatment for large spontaneous basal ganglia hemorrhage: retrospective analysis of 253 cases. Br J Neurosurg. 2013 Oct;27(5):617-21.

13. Li Y, Yang R, Li Z, Yang Y, Tian B, Zhang X, et al. Surgical Evacuation of Spontaneous Supratentorial Lobar Intracerebral Hemorrhage: Comparison of Safety and Efficacy of Stereotactic Aspiration, Endoscopic Surgery, and Craniotomy. World Neurosurg. 2017 Sep;105:332-40.

14. Luo JB, Peng B, Quan W, Cao ZK, Xiao GC, Lu JP, et al. Therapeutic effects of aspiration with a directional soft tube and conservative treatment on mild hemorrhage in the basal ganglion]. Nan Fang Yi Ke Da Xue Xue Bao. 2008 Aug;28(8):1352-3.

15. Mayer SA, Rincon F. Treatment of intracerebral haemorrhage. Lancet Neurol. 2005 Oct;4(10):662-72.

16. Mendelow AD, Gregson BA, Fernandes HM, Murray GD, Teasdale GM, et al. Early surgery versus initial conservative treatment in patients with spontaneous supratentorial intracerebral haematomas in the International Surgical Trial in Intracerebral Haemorrhage $(\mathrm{STICH})$ : a randomised trial. Lancet. 2005 Jan 29-Feb 4;365(9457):387-97.

17. Mendelow AD, Gregson BA, Rowan EN, Murray GD, Gholkar A, Mitchell PM, et al. Early surgery versus initial conservative treatment in patients with spontaneous supratentorial lobar intracerebral haematomas (STICH II): a randomised trial. Lancet. 2013 Aug 3;382(9890):397-408

18. Nagasaka $T$, Tsugeno M, Ikeda $H$, Okamoto $T$, Inao $S$, Wakabayashi T. Early recovery and better evacuation rate in neuroendoscopic surgery for spontaneous intracerebral hemorrhage using a multifunctional cannula: preliminary study in comparison with craniotomy. J Stroke Cerebrovasc Dis. 2011 May-Jun;20(3):208-13.

19. Ohwaki K, Yano E, Nagashima H, Hirata M, Nakagomi T, Tamura A. Surgery for patients with severe supratentorial intracerebral hemorrhage. Neurocrit Care. 2006;5(1):15-20. 
20. Prasad K, Browman G, Srivastava A, Menon G. Surgery in primary supratentorial intracerebral hematoma: a meta-analysis of randomized trials. Acta Neurol Scand. 1997 Feb;95(2):103-10.

21. Teernstra OP, Evers SM, Lodder J, Leffers P, Franke CL, Blaauw G, et al. Stereotactic treatment of intracerebral hematoma by means of a plasminogen activator: a multicenter randomized controlled trial (SICHPA). Stroke. 2003 Apr;34(4):968-74.

22. van Asch CJ, Luitse MJ, Rinkel GJ, van der Tweel I, Algra A, Klijn CJ. Incidence, case fatality, and functional outcome of intracerebral haemorrhage over time, according to age, sex, and ethnic origin: a systematic review and meta-analysis. Lancet Neurol. 2010 Feb;9(2):167-76.

23. Wang WH, Hung YC, Hsu SP, Lin CF, Chen $\mathrm{HH}$, Shih $\mathrm{YH}$, et al. Endoscopic hematoma evacuation in patients with spontaneous supratentorial intracerebral hemorrhage. J Chin Med Assoc. 2015;78(2):101-7.

24. Xi G, Wagner KR, Keep RF, Hua Y, de Courten-Myers GM, Broderick JP, et al. Role of blood clot formation on early edema development after experimental intracerebral hemorrhage. Stroke. 1998 Dec;29(12):2580-6.

25. Xu X, Chen X, Li F, Zheng X, Wang Q, Sun G, et al Effectiveness of endoscopic surgery for supratentorial hypertensive intracerebral hemorrhage: a comparison with craniotomy. J Neurosurg. 2018 Feb;128(2):553-9.

26. Yamashiro S, Hitoshi Y, Yoshida A, Kuratsu J. Effectiveness of Endoscopic Surgery for Comatose Patients with Large Supratentorial Intracerebral Hemorrhages. Neurol Med Chir (Tokyo). 2015;55(11):819-23.

27. Zhang HZ, Li YP, Yan ZC, Wang XD, She L, Wang $\mathrm{XD}$, Dong L. Endoscopic evacuation of basal ganglia hemorrhage via keyhole approach using an adjustable cannula in comparison with craniotomy. Biomed Res Int. 2014;2014:898762.

28. Zhou H, Zhang Y, Liu L, Huang Y, Tang Y, Su J, et al. Minimally invasive stereotactic puncture and thrombolysis therapy improves long-term outcome after acute intracerebral hemorrhage. J Neurol. 2011 Apr;258(4):661-9. 